\title{
Características Físico-Mecânicas do Couro de Ovinos Mestiços Santa Inês e Texel
} Arturo Bernardo Selaive Villarroel ${ }^{1}$, Roberto Germano Costa ${ }^{2}$, Sônia Maria Pinheiro Oliveira ${ }^{3}$

\footnotetext{
RESUMO - Objetivou-se, neste estudo, avaliar as características físico-mecânicas de couros de ovinos mestiços $\mathrm{F}_{1}$ provenientes de cruzamentos de ovelhas deslanadas sem raça definida (SRD) com carneiros das raças lanada Texel (TE) e deslanada Santa Inês (SI). Foram avaliadas 22 peles de borregos abatidos com idade média de 240 dias e peso corporal de 21,93 \pm 4,38 e 20,91 \pm 3,40 kg, respectivamente, para os mestiços de TE e SI. Após a esfola, as peles foram pesadas, conservadas por salmouragem e salga e avaliadas no curtume. Inicialmente, foram curtidas ao cromo-estagio de wet blue e, posteriormente, dos couros semi-acabados, foram retirados do lado direito corpos-de-prova nas posições paralela e perpendicular ao eixo crânio-caudal das regiões paleta, anca e ventre, para a determinação dos ensaios físico-mecânicos de resistência à tração e ao rasgamento progressivo. O delineamento experimental para análises dos dados foi o de parcelas subdivididas, tendo como parcelas dois grupos genéticos e como subparcelas o fatorial 2 x 3 (duas posições e três regiões), com três repetições, sendo os valores médios comparados pelo teste de Tukey. Os couros dos ovinos deslanados mestiços SI apresentaram maior resistência aos ensaios de tração e rasgamento progressivo que o couros dos animais mestiços Texel, havendo, em ambos os grupos, diferenças significativas de espessura e resistência entre as diferentes regiões dos couros estudados. Concluiu-se que os couros oriundos do cruzamento do ovino lanado Texel com ovelhas SRD apresentam menor qualidade industrial que os couros de animais mestiços deslanados Santa Inês.
}

Palavras-chave: cruzamento, ensaios físico-mecânicos, pele, qualidade do couro

\section{Physical-Mechanic Leathers Characteristics of Crossbred Santa Inês and Texel Sheep}

ABSTRACT -This work aimed to evaluate the physical-mechanic characteristics of crossed sheep leathers from hairy tropical crioula ewes mated with Texel wooly breed (TE) and Santa Inês (SI) hair tropical breed rams. Twenty two skin were evaluated from male sheep slaughtered at average of 240 days of age and $21.9 \pm 4.4$ and $20.9 \pm 3.4$ body live weight, respectively for TE and SI. After skinning, pelts were weighed, conserved in brine and salted and classified by quality before the chromium-tanned. From the leather obtained in this stage, called wet blue, samples were taken from palette, hind and ventral regions. From each region studied, three samples were taken in two directions for physical-mechanical analysis of tension and tear resistance. A split plot experimental design was used, where the two genetic groups were represented by the plots and a 2 x 3 factorial (two positions and three regions) by the split plots. Results showed that the SI leathers group had better resistance to tensile strength and distention assays than TE group and, in both genetic group, there were not significant differences among the different regions studied on leather. It was concluded that leathers from the crossbreding of Texel sheep wooly ram and crioula hairy ewes showed smaller industry quality than hair tropical Santa Inês breed.

Key Words: crossbreed, physical-mechanical characteristics, skin, leather quality

\section{Introdução}

A criação de ovinos no nordeste tem alcançado novos espaços com a implantação de pólos industriais de produtos, como carne e pele, tendo esta última, grande aceitação nos mercados nacional e internacional. Entretanto, grande proporção das peles não satisfaz as exigências do mercado e/ou da indústria de curtimento.

Para efeito da comercialização industrial, a pele deve apresentar certos requisitos, de acordo com a utilização do produto final, que pode ser afetado por fatores que vão desde a qualidade da pele oferecida pelo produtor até sua transformação em couro no curtume, englobando tanto os fornecedores de matéria-prima como a indústria de processamento (Costa et al., 1998).

O clima semi-árido do nordeste favorece a qualidade das peles, em razão, principalmente, de sua estrutura adaptada ao clima quente, de modo que a cobertura de lã foi gradualmente substituída por pêlos. Entretanto, com a introdução de animais de raças lanadas na região, visando melhorar o potencial de produção de

\footnotetext{
${ }^{1}$ Professor do Departamento de Zootecnia da UFC. Bolsista do CNPq. Endereço eletrônico: selaive@ufc.br.

2 Professor do Centro de Formação de Tecnólogos, Campus IV da UFPB. Endereço eletrônico: rgermano@cft.ufpb.br

${ }^{3}$ Professor do Departamento de Zootecnia da UFC. Endereço eletrônico: soniace@ufc.br
} 
carne das raças nativas, pode haver alterações nas características desejáveis das peles e reduzir seu valor comercial no mercado, em razão da menor qualidade industrial das peles lanadas (Jacinto, 1996).

A uniformidade e a qualidade do produto dependem de um programa amplo de controle de produção. Hoinacki (1989) afirma que a realização de ensaios físico-mecânicos é uma forma de garantir essa qualidade, uma vez que as propriedades físicas estão relacionadas à composição química do couro.

Objetivou-se, com este trabalho, avaliar as características de qualidade dos couros de peles de animais mestiços lanados Texel e deslanados Santa Inês, por meio de ensaios físico-mecânicos de resistência à tração e ao rasgamento progressivo.

\section{Material e Métodos}

Foram utilizadas 22 peles de ovinos mestiços machos inteiros - 13 oriundas do cruzamento de ovelhas deslanadas sem raça definida (SRD) com carneiros puros da raça lanada Texel (TE) e nove de mestiços deslanados Santa Inês x SRD (SI). Cada grupo genético de matrizes foi acasalado com três reprodutores utilizados, individualmente, em rotação semanal, para evitar o efeito do reprodutor. As crias mestiças foram manejadas em sistema semi-extensivo de produção e abatidas com média de $236 \pm 5,7$ e $247 \pm 11$,4 dias de idade e peso corporal de 21,9 \pm 4,3 e 20,9 $\pm 3,4 \mathrm{~kg}$, respectivamente, para os mestiços TE e SI.

Imediatamente após a esfola, as peles foram pesadas, identificadas de acordo com os grupos genéticos e conservadas pelo sistema de salmouragem e salga, conforme as técnicas descritas na literatura (Silva Sobrinho \& Jacinto, 1992; CTCCA, 1994; Dal Monte, 1998).

As peles foram curtidas de acordo com a metodologia descrita por Silva Sobrinho \& Jacinto (1992), obedecendo as etapas do remolho, caleiro, desencalagem, purga, desengraxe, píquel, curtimento, basificação, neutralização, recurtimento e engraxe. As peles foram curtidas utilizando-se como produto químico curtente o sulfato de cromo.

Os couros semi-acabados foram submetidos aos ensaios físico-mecânicos de tração e rasgamento progressivo, segundo as normas da Associação Brasileira de Normas Técnicas-ABNT para o setor coureiro (ABNT, 1988; 1990; 1997abc; 1998). Dos couros, foram tomados pedaços de amostras (cor- pos-de-prova) das regiões paleta, anca e ventre, áreas oficiais de amostragem para estes tipos de análises.

Os couros foram climatizados durante 48 horas à temperatura de $23 \pm 2^{\circ} \mathrm{C}$ e umidade relativa de $50 \pm$ $5 \%$, antes da realização dos ensaios. Para retirada dos corpos-de-prova em cada ensaio, usou-se o balancim (prensa hidráulica modelo BHV 22) e as navalhas de dimensões e formato padronizados pelas respectivas normas.

Foram retirados seis corpos-de-prova do lado direito dos couros, sendo três paralelos e três perpendiculares à linha dorsal, para as determinações de resistência à tração e ao alongamento e da força de rasgamento progressivo. No Laboratório de Ensaio, foram realizadas as medidas de espessura das amostras por intermédio do espessímetro e, posteriormente, as amostras foram avaliadas num dinamômetro de marca ZWICK/ Z 2.5, acoplado a um computador com o programa "Test x pert standard test programs", para os ensaios de tração e rasgamento progressivo.

Para análises dos dados, utilizou-se o delineamento experimental com parcelas subdivididas tendo como parcelas os dois grupos genéticos, como subparcelas o fatorial 2 x 3 (duas posições e três regiões), com três repetições, sendo um grupo genético de treze e outro de nove animais. As médias dos resultados para os ensaios físico-mecânicos foram comparadas pelo teste de Tukey a 5\% de probabilidade, empregando-se o procedimento de análise de variância do SAS (1999).

\section{Resultados e Discussão}

A análise de variância dos resultados obtidos nos ensaios físicos-mecânicos de tração e de rasgamento progressivo comprovou um efeito significativo $(\mathrm{P}<0,05)$ do grupo genético no parâmetro resistência, sendo as peles dos ovinos mestiços Santa Inês mais resistentes que as dos mestiços Texel. No ensaio de tração, os valores médios foram de 171,62 kgf/ $\mathrm{cm}^{2}$ nos couros dos mestiços Santa Inês e de $122,88 \mathrm{kgf} / \mathrm{cm}^{2}$ nos mestiços Texel e, para o rasgamento progressivo, foram de 37,92 e 32,86 kgf/cm, respectivamente, para os couros de animais mestiços Santa Inês e Texel (Tabela 1).

Como o ovino Texel é uma raça lanada, era de se esperar que seus mestiços apresentassem peles com menor resistência, considerando que estudos relatados na literatura afirmam que as peles dos ovinos lanados são de menor resistência que as dos 
Tabela 1 - Médias obtidas para o ensaio físico-mecânico de tração e rasgamento progressivo nos couros dos ovinos mestiços, segundo o grupo genético

Table 1 - Observed means for physical mechanical characteristics of strenght and tearing progressive of leather of sheep, considering genetics group

\begin{tabular}{|c|c|c|}
\hline $\begin{array}{l}\text { Fontes de variação } \\
\text { Sources of variation }\end{array}$ & $\begin{array}{l}\text { Mestiço } \\
\text { Texel } \\
\text { Half-breed } \\
\text { Texel } \\
\end{array}$ & $\begin{array}{c}\text { Mestiço } \\
\text { Santa Inês } \\
\text { Half-breed } \\
\text { Santa Inês }\end{array}$ \\
\hline \multicolumn{3}{|l|}{ Tração } \\
\hline \multicolumn{3}{|l|}{ Tensile } \\
\hline $\begin{array}{l}\text { Espessura }(\mathrm{mm}) \\
\text { Thickness (mm) }\end{array}$ & $0,76^{\mathrm{a}}$ & $0,74^{\mathrm{a}}$ \\
\hline $\begin{array}{l}\text { Resistência }\left(\mathrm{kgf} / \mathrm{cm}^{2}\right) \\
\text { Strength }\left(\mathrm{kgf} / \mathrm{cm}^{2}\right)\end{array}$ & $122,88^{b}$ & $171,62^{\mathrm{a}}$ \\
\hline $\begin{array}{l}\text { Alongamento (\%) } \\
\text { Elongation (\%) }\end{array}$ & $35,77^{a}$ & $37,23^{\mathrm{a}}$ \\
\hline \multicolumn{3}{|l|}{ Rasgamento progressivo } \\
\hline $\begin{array}{l}\text { Tearing progressive } \\
\text { Espessura (mm) }\end{array}$ & $0,75^{\mathrm{a}}$ & $0,76^{\mathrm{a}}$ \\
\hline $\begin{array}{l}\text { Resistência }(\mathrm{kgf} / \mathrm{cm}) \\
\text { Strength }(\mathrm{kgf} / \mathrm{cm})\end{array}$ & $32,86^{b}$ & $37,92^{\mathrm{a}}$ \\
\hline
\end{tabular}

deslanados (Pimenta, 1979; Jacinto, 1996). As diferenças podem ser atribuídas às características estruturais da pele dos diferentes grupos genéticos, com arranjos diferentes das fibras de colágeno, estruturas responsáveis pela textura e resistência do couro (Ferrandiz-Gomez et al., 1993). A maior resistência das peles dos ovinos deslanados também poderia ser explicada pela maior espessura em relação às dos ovinos lanadas (Jacinto, 1996), fato não observado neste estudo. Os couros mestiços Santa Inês apresentaram espessura similar à dos mestiços Texel $(0,74$ x $0,76 \mathrm{~mm}$ e 0,76 x 0,75 mm, respectivamente, para os ensaios de tração e rasgamento) (Tabela 1). Por outro lado, deve-se destacar que as peles avaliadas neste estudo eram de ovinos jovens (oito meses de idade) e a resistência tende a ser maior à medida que a idade do animal avança (Costa et al., 1998). Portanto, a resistência dos couros originados de peles de animais deslanados pode ser ainda maior em animais adultos.

No ensaio de rasgamento progressivo, o valor médio encontrado $(37,92 \mathrm{kgf} / \mathrm{cm})$ nos couros dos

Tabela 2 - Médias obtidas para os ensaios físico-mecânicos de tração e rasgamento progressivo nos couros dos ovinos mestiços, considerando a região e posição das amostras

Table 2 - Observed means for physical mechanical characteristics (assay) of strenght of leather of sheep, considering region and position of sample

\begin{tabular}{|c|c|c|c|c|c|}
\hline \multirow[b]{2}{*}{$\begin{array}{l}\text { Fontes de variação } \\
\text { Sources of variation }\end{array}$} & \multicolumn{3}{|c|}{$\begin{array}{l}\text { Tração } \\
\text { Tensile }\end{array}$} & \multicolumn{2}{|c|}{$\begin{array}{c}\text { Rasgamento progressivo } \\
\text { Tearing progressive }\end{array}$} \\
\hline & $\begin{array}{c}\text { Espessura } \\
(\mathrm{mm}) \\
\text { Thickness (mm) }\end{array}$ & $\begin{array}{c}\text { Resistência } \\
\left(\mathrm{kgf} / \mathrm{cm}^{2}\right) \\
\text { Strength }\left(\mathrm{kgf} / \mathrm{cm}^{2}\right)\end{array}$ & $\begin{array}{c}\text { Alongamento } \\
(\%) \\
\text { Elongation (\%) }\end{array}$ & $\begin{array}{c}\text { Espessura } \\
(\mathrm{mm}) \\
\text { Thickness }(\mathrm{mm})\end{array}$ & $\begin{array}{c}\text { Resistência } \\
(\mathrm{kgf} / \mathrm{cm}) \\
\text { Strength }(\mathrm{kgf} / \mathrm{cm})\end{array}$ \\
\hline $\begin{array}{l}\text { Região } \\
\text { Region }\end{array}$ & & & & & \\
\hline $\begin{array}{l}\text { Paleta } \\
\text { Palette }\end{array}$ & $0,78^{\mathrm{a}}$ & $162,54^{\mathrm{a}}$ & $36,17^{a}$ & $0,75^{\mathrm{b}}$ & $37,90^{\mathrm{a}}$ \\
\hline $\begin{array}{l}\text { Anca } \\
\text { Rump }\end{array}$ & $0,77^{\mathrm{a}}$ & $154,08^{\mathrm{ab}}$ & $37,07^{\mathrm{a}}$ & $0,81^{\mathrm{a}}$ & $37,96^{\mathrm{a}}$ \\
\hline $\begin{array}{l}\text { Ventre } \\
\text { Belly } \\
\text { Posição } \\
\text { Position }\end{array}$ & $0,69^{\mathrm{b}}$ & $138,38^{\mathrm{b}}$ & $36,66^{\mathrm{a}}$ & $0,71^{\mathrm{b}}$ & $31,69^{b}$ \\
\hline $\begin{array}{l}\text { Perpendicular } \\
\text { Perpendicular }\end{array}$ & $0,75^{\mathrm{a}}$ & $156,73^{\mathrm{a}}$ & $34,93^{\mathrm{a}}$ & $0,75^{\mathrm{a}}$ & $35,62^{\mathrm{a}}$ \\
\hline $\begin{array}{l}\text { Paralela } \\
\text { Parallel }\end{array}$ & $0,74^{\mathrm{a}}$ & $146,64^{\mathrm{a}}$ & $38,34^{\mathrm{a}}$ & $0,77^{\mathrm{a}}$ & $36,09^{a}$ \\
\hline
\end{tabular}

Valores seguidos por letras distintas, na mesma coluna, indicam diferença significativa a $5 \%(P<0,05)$, pelo teste de Tukey. Values followed by diffrent letters in same column, indicate significant difference at $5 \%(P<.05)$ by Tukey test. 
mestiços Santa Inês indica serem adequados para confecção de napas de vestuário de boa qualidade, considerando o valor mínimo de $35 \mathrm{kgf} / \mathrm{cm}$ requerido em couros bovinos (BASF, 1984).

A resistência e espessura dos couros de ambos os grupos genéticos apresentaram variação significativa $(\mathrm{P}<0,05)$ entre as regiões anca, paleta e ventre, porém, não foram observadas variações no alongamento, (Tabela 2). As diferenças eram esperadas, considerando-se que a estrutura e a espessura da pele dos animais domésticos variam entre as diferentes regiões, em decorrência de variações no tipo e na quantidade do pelame, na distribuição e no tipo de glândulas e de adaptações funcionais que ajustam o organismo ao ambiente externo (Banks, 1992). Além disso, são influenciadas pela raça, pela idade e pelo sexo do animal (Bal, 1984).

A espessura das regiões da paleta $(0,78 \mathrm{~mm})$ e da anca $(0,77 \mathrm{~mm})$ foram significativamente $(\mathrm{P}<0,05)$ superiores à do ventre $(0,69 \mathrm{~mm})$. Da mesma forma, a resistência foi maior $(\mathrm{P}<0,05)$ na região da paleta que na do ventre, fato não observado por Jacinto (1996), em ovinos lanados da raça Ideal. Sabe-se que a zona do grupão é a região mais rica em fibras de colágeno, com melhor entrelaçamento entre si, enquanto a região do flanco é uma zona pobre em fibras de colágeno, com entrelaçamento mais fraco em relação às demais zonas. Segundo Henrickson et al. (1984), a pele de ovinos tem menor conteúdo de fibras colágenas que a de caprinos e tende a ser menos espessa nos locais de flexão, como ventre, joelho e pescoço, o que justifica os baixos valores médios para a maioria dos parâmetros estudados na região do ventre. As médias dos parâmetros de posição não apresentaram diferenças significativas $(\mathrm{P}>0,05)$ entre os couros de ambos os grupos genéticos, resultado similar aos observados por Dal monte (1998) e Jacinto (1996).

\section{Conclusões}

Couros de animais mestiços deslanados Santa Inês apresentaram maior resistência à tração que os mestiços lanados Texel, aspecto importante na determinação da qualidade do produto pela indústria coureira. Portanto, o uso em cruzamento de reprodutores lanados com ovelhas deslanadas, para melhorar a produção de carne dos ovinos no nordeste influencia negativamente a qualidade dos couros, fato que deve ser considerado na avaliação da utilização de reprodutores lanados.

\section{Agradecimento}

Às empresas Bermas Indústria e Comércio Ltda e CV. Couros e Peles Ltda, pelas facilidades para execução do projeto, pela estrutura laboratorial e pela disponibilização de pessoal.

\section{Literatura Citada}

ASSOCIAÇÃO BRASILEIRA DE NORMAS TÉCNICAS. NBR 11035, NB 1199: corte de corpos-de-prova em couro. Rio de Janeiro, 1990. 1 p.

.NBR 11052, MB 2984: couros - determinação da espessura. Rio de Janeiro, 1997a. 3p.

.NBR 11055, MB 3015: couro - determinação da força de rasgamento progressivo. Rio de Janeiro, 1997c. 4p.

.NBR 11041, MB3013: couros-determinação da resistência à tração e alongamento. Rio de Janeiro, 1997b. 5p.

.NBR 10455, NB 1123: climatização de materiais usados na fabricação de calçados e correlatos. Rio de Janeiro, 1988. 3p. .NBR 11032, NB 1196: peles e couros - tomada de pedaço-de-prova - procedimento. Rio de Janeiro, 1998. 4p.

BAL, H.S. Pele. In: Dukes fisiologia dos animais domésticos. 10.ed. Rio de Janeiro: Guanabara Koogan, 1984. p.469-477.

BANKS, W.J. Sistema tegumentar. In: Histologia veterinária aplicada. 2.ed. São Paulo: Manole, 1992. p.391-402.

BASF. Vademécum para el técnico en curtición. 2.ed. Ludwigshafen: 1984. 441p.

CENTRO TECNOLÓGICO DO COURO CALÇADOS E AFINS. A fabricação do couro. Novo Hamburgo, 1994. 44p. (Série Couro Calçados e Afins, 1).

COSTA, R.G.; PIMENTA FILHO, E.C.; SILVA, A.F.R. et al. Efeito da idade do animal na qualidade do couro de caprinos criados em regime semi - extensivo. Revista Brasileira de Zootecnia, v.27, n.2, p.355-358, 1998.

DAL MONTE, M.A.B.L. Avaliação anátomo-histológica e física-mecânica de peles de caprinos em idades diferenciadas. Areia: Universidade Federal da Paraíba, 1998. 53p. Dissertação (Mestrado em Zootecnia) - Universidade Federal da Paraíba, 1998.

FERRANDIZGOMEZ, T.P.; ALMELA, M.; MARTINMARTINEZ, J.M. et al. Effect of skin type and direction of applied force on peel strength of skin layers. Journal of the Society of Leather Technologists and Chemists, v.77, n.4, p.115-122, 1993.

HENRICKSON, R. L.; RANGANAYAKI, M. D.; ASGHAR, A. Age, species, breed, Sex, and nutrition effect on hide collagen. CRC Critical Reviews in Food Science and Nutrition, v.20, n.3, p.159-172, 1984.

HOINACKI, E. Peles e couros: origens, defeitos e industrialização. 2.ed. Porto Alegre: CPF SENAI de Artes Gráficas "Henrique d“Ávila Bertaso”, 1989. 320p.

JACINTO, M.A.C. Características anátomo-estruturais da pele de ovinos (Ovis áries L.) lanados e deslanados, relacionadas com o aspecto físico-mecânico do couro após o curtimento. Jaboticabal: Universidade Estadual de São Paulo, 1996. 90p. Dissertação (Mestrado em Zootecnia) - Universidade Estadual de São Paulo, 1996. 
PIMENTA, J.T.S. Estudo histológico da pele de ovinos (Ovis aries) criados no nordeste brasileiro. Rio de Janeiro: Universidade Federal do Rio de Janeiro, 1979. 76p. Dissertação (Mestrado em Histologia) - Universidade Federal do Rio de Janeiro, 1979.

STATISTICAL ANALYSES SYSTEM - SAS. The SAS system for windows. version 8.0. Cary: 1999.
SILVA SOBRINHO, A.G.; JACINTO, M.A.C. Peles ovinas. Jaboticabal: FUNEP, 1992. 33p.

Recebido em: 04/02/03

Aceito em: $26 / 07 / 04$ 